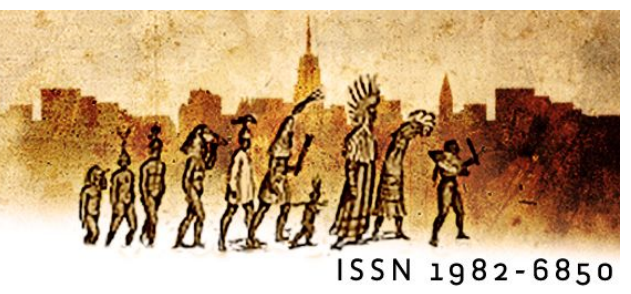

\title{
Algumas relações entre Narrativas, Romance e a Psicologia Experimental da Cognição Literária e Habilidades Sociais
}

\author{
Gabriel José Corrêa Mograbi' (UFMT)
}

Resumo: Análise e revisão de dois artigos-alvo no campo da psicologia experimental que focam a relação entre sensibilidades interpessoais e a exposição a narrativas ficcionais, com especial ênfase nos resultados sobre o Romance.

Palavras-chave: Estudos Cognitivos de Literatura, Psicologia Experimental, Teoria da Mente, Sensibilidade Interpessoal, Habilidades Sociais, Gêneros Literários, Romance.

\begin{abstract}
Analysis and review of two target-articles in the field of experimental psychology, focusing on the relationship between interpersonal sensibility and exposure to fictional narratives, with special emphasis on the results on Romance.
\end{abstract}

Keywords: Cognitive Studies in Literature, Experimental Psychology, Theory of Mind, Interpersonal Sensitivity, Social Skills, Literary Genres, Romance.

\section{Introdução}

Recognition, as the name indicates, is a change from ignorance to knowledge, producing love or hate between the persons destined by the poet for good or bad fortune.

-Aristóteles, Poetics, Parte XI.

What is realized in the novel is the process of coming to know one's own language as it is perceived in someone else's language, coming to know one's own belief system in someone else's system.

- Mikhail Bakhtin, The Dialogic Imagination: Four Essays. 
Gostaria de continuar de onde parei... No último parágrafo de meu artigo intitulado "Sobre Naturalismos, Resistências Humanistas e a possibilidade de Diálogo", publicado na última edição de Eutomia, no dossiê temático capitaneado por Pedro Dolabela Chagas e por mim mesmo, afirmei:

A consiliência, a ser construída para viabilizar uma teoria como a preconizada pelos estudos literários de base naturalista, teria de ser conquistada, justamente, em esferas de saber que vão muito além da mera psicologia evolutiva, seja ela mais ou menos modular ou generalista. É essa interação de módulos e de tecidos multifuncionais do neocórtex que precisa ser explorada. Certamente, os diversos ramos das neurociências, em seus diversos níveis de investigação causal, as várias áreas das ciências biológicas do nível molecular ao populacional, as várias vertentes da psicologia experimental e as formas de ciências humanas aptas a diálogos consilientes terão de ser incluídos nesta pesquisa. Isto não desabona por completo os estudos literários evolutivos, que merecem o nosso respeito enquanto uma tentativa de ir além de uma zona de conforto departamental. Eles são uma brava tentativa de ir além de um modelo humanista desgastado que, ao defender uma pura liberdade semântica na construção cultural, recai em formas mais ou menos caudatárias de dualismos velhos ou renovados. Entretanto, basta escolher um ponto nevrálgico do debate - a gênese (do conjunto) da(s) capacidade(s) humanas para a linguagem - para se notar a necessidade de uma consiliência muito maior (MOGRABI, 2015, p. 442-443).

Considerando o que afirmei sobre a necessidade de uma consiliência muito maior para uma fundamentação mais abrangente e sólida dos estudos literários naturalistas contemporâneos, procurarei neste artigo estudar algumas referências fundamentais no que concerne à psicologia experimental voltada à literatura. Como é afirmado no próprio parágrafo, a tarefa hercúlea de naturalização da teoria literária pressuporia uma capacidade de integração de muitas áreas distintas que aqui não será operada. No entanto, dando sequência ao artigo anterior, procurarei, de maneira razoavelmente pormenorizada, efetuar uma análise de dois estudos de psicologia experimental que, de maneira surpreendentemente sólida e perspicaz, foram capazes de abordar, a partir de protocolos empíricos laboratoriais, temas caros à literatura, o que por si só constitui mérito notável. Ainda neste último parágrafo de meu artigo publicado na edição anterior e citado acima, inseri nota de fim de página justaposta à palavra "pesquisa":

Por exemplo, estudos capitaneados por Raymond Mar, Demis Hassabis, Nathan Spreng, e colegas (não citados por nenhum dos literatos evolutivos) 
mostram alguns tipos de abordagens diretas da competência literária pela via da neurociência e da psicologia experimental que podem ser futurosas. (MOGRABI, 2015, p. 443)

São justamente alguns destes artigos que aqui me interessam e que serão analisados. Curiosamente nenhuma destas referências é abordada ou sequer citada em quaisquer textos de quaisquer dos autores defensores do assim chamado Darwinismo Literário. $\mathrm{Na}$ verdade, existem alguns poucos laboratórios de neurociência e psicologia experimental que vêm se direcionando para a construção de interfaces entre estas ciências e a literatura como seu objeto.

Falando em objeto, deixe-se muito bem definido o alvo de nosso artigo: a relação entre a exposição à narrativa ficcional e capacidades e sensibilidades sociais. Se o fito no início da concepção desse artigo era ser mais panorâmico e fazer uma apresentação mais geral e superficial de uma gama maior de referências e temas, no processo da escritura enveredamos por uma senda mais fechada. Basta de metaintencionalidade por ora e vamos ao nosso objeto.

O laboratório de Raymond A. Mar, professor do departamento de psicologia da York University de Toronto, vem operando pesquisas revolucionárias há mais de 10 anos no que concerne a uma abordagem científica da literatura. Ainda que o laboratório de Mar não seja o único a trabalhar com o tema, talvez não haja na face da terra muitos outros centros de pesquisa que tenham ido tão fundo neste tipo de pesquisa com volume de publicação até então. Todos sabemos que pesquisas realizadas em poucos laboratórios e com pouca replicação não são geralmente consideradas sólidas na ciência atual. No entanto, é bastante surpreendente a conjugação de profunda inovação com a busca de rigor desse time de pesquisa que gravita em torno de Raymond Mar. Sua capacidade de transformar temas eminentemente "humanísticos", de operacionalização extremamente difícil, em protocolos testáveis e estatisticamente relevantes é, já em si mesma, uma nota de esperança na possibilidade de diálogo interdisciplinar e uma lição de consiliência. Faço notar que o time de Mar e Colegas e os times de colaboradores com os quais Mar interage têm experimentos e resultados neurocientíficos muito interessantes já publicados, no entanto, por uma questão de limitações de páginas, tempo e precisão de escopo, analisarei profundamente duas publicações apenas desse grupo, no campo da psicologia experimental, e farei referência a umas quantas outras apenas como vias de esclarecimento desses 2 artigos-alvo. 
Mais metalinguagem: reconheço que o artigo aqui ofertado não tem qualquer caráter revolucionário ou inovador. É apenas um redescrição crítica dos próprios artigos ou, quase, uma tradução resumida porém comentada. Inovadores ou revolucionários, talvez, sejam os estudos aqui focalizados. É importante notar que a exposição aqui iniciada não buscará estar pautada em tecnicismos ou jargões científicos, nem nos modos cientificamente preconizados para revisões de literatura (reviews) em revistas de ciência, muito mais sistemáticos, entretanto muito pouco descritivos e explicativos e sempre contando com um número muito maior de citações, mas com muito menos atenção dedicada a cada um dos experimentos citados. Este artigo é apenas uma tentativa singela de tornar acessíveis e palatáveis, ao público de língua portuguesa não especializado em psicologia experimental, alguns resultados destas últimas áreas que focalizam estudos promissores tendo como objeto a literatura. Entendo que o público para o qual escrevo é leigo em ciência, mas, de alguma maneira, interessado em conhecer estudos cognitivos em literatura. Sejam literatos, filósofos ou outros pesquisadores de formação humanista, todos dentre estes que possam estar interessados nas capacidades cognitivas envolvidas na leitura de literatura, na psicologia de capacidades sociais e sua relação com empatia e projeção em narrativas, teoria da mente e sua relação com os temas já aqui citados podem, de alguma forma, tirar certo proveito desse escrito. A natureza do trabalho aqui apresentado é "angélica" no sentido mais original do termo: hermenêutica de divulgação em favor da consiliência. Poupo a vocês, meus leitores, o trabalho de ler originais de áreas que não lhes são aparentemente próximas. Advirto também que os resultados experimentais aqui analisados não são livres de problemas, nem poderiam ter caráter dedutivo. São explorações de novos paradigmas que ousam estudar questões que muitos cientistas "duros" considerariam insondáveis. São estudos que, como grande parte da ciência atual, apresentam correlações estatísticas mais ou menos sólidas e que sugerem possíveis relações causais, mas não as afirmam ou vindicam-nas de maneira taxativa ou peremptória.

\section{1. "Ratos de Biblioteca" 3 x o "Nerds"}

Em um artigo intitulado "Bookworms versus nerds: Exposure to Fiction versus nonFiction, divergent associations with social ability, and the simulation of Fictional social worlds", 
Raymond A. Mar, Keith Oatley, Jacob Hirsh, Jennifer dela Paz, Jordan B. Peterson investigaram a diferença de capacidades sociais de leitores assíduos de obras ficcionais e não ficcionais. Antes de tudo, registro aqui o meu pouco apreço pelo título do artigo. Eu, sinceramente, tenho dificuldades com a rotulação estereotípica de pessoas. Notadamente, o título é pensado para ser um chamariz de leitores. Mas vocês verão no decorrer de minha análise que o artigo acaba por surpreender algumas concepções do senso comum, pelo menos no que concerne a uma dessas categorias.

Em linhas gerais, os resultados indicam que leitores assíduos de obras ficcionais teriam melhores resultados em testes que medem capacidades sociais em comparação com leitores assíduos de obras puramente não ficcionais. Os autores entendem que a capacidade de compreensão de personagens em narrativas ficcionais está fortemente correlacionada com a capacidade de compreensão e empatia com personagens reais. A capacidade de se tornar absorto em uma narrativa também prediria bons resultados empáticos. Visando dar corpo empírico às intuições de pensadores que vão desde Aristóteles (2008/original de 335 a.C.) a Nussbaum (1995), passando por Carruthers e Smith (1996), Frith e Frith (2001) entre outros $^{1}$, Mar e colegas criaram designs experimentais para avaliar as correlações entre as capacidades de interpretação, projeção e envolvimento com narrativas e a capacidade de projeção e empatia em situações sociais.

Como os próprios autores estabelecem, naturalmente, a correlação positiva entre leitura de narrativas e a posse de capacidades sociais poderia ter pelo menos três diferentes explicações:

a) A hipótese que mais lhes interessa e que consideram a mais viável é a de que o contato com narrativas favorece e desenvolve a cognição social à medida que familiariza o leitor com situações ficcionais nas quais uma inteligência social é requerida e o conhecimento de situações complexas entre personagem ficcionais é passível de transposição para situações reais presentes no cotidiano social.

b) A narrativa afiaria capacidades sociais, funcionando como um aperfeiçoamento de tais capacidades exercidas no mundo real.

1 Todos autores citados pelos próprios signatários de nosso artigo em tela. 
c) E, claro, a hipótese que menos os atrai, mas ainda assim logicamente viável, de que pessoas que já dispõem de intensas habilidades sociais e grandes capacidades empáticas são justamente aquelas que mais se comprazem em ler narrativas.

É, de novo, importante fazer notar que os próprios autores reconhecem que tais hipóteses não são mutuamente excludentes e que é muito possível que se combinem de alguma forma. Mas, de novo, deve-se concordar com os autores que um refinamento explicativo da maneira pela qual cada uma dessas hipóteses poderia ser causalmente relevante, passa primeiro pela demonstração de que existe uma correlação positiva entre a leitura de narrativa e a posse de capacidades ou conhecimentos sociais mais eficazes.

\subsection{População}

Como é relatado pelos autores, o referido estudo contou com população de 94 participantes (sendo 63 mulheres) ligados à comunidade da University of Toronto. 46 destes eram estudantes de psicologia e tomaram parte no estudo motivados por créditos em uma disciplina, enquanto o resto recebeu um pró-labore de 15 dólares canadenses e foram contratados a partir de pôsteres em murais na universidade. Ainda que eu já tenha elogiado o estudo e o grupo de pesquisa aqui abordado, faço notar que, em minha visão, não é a medida mais cientificamente kosher dispor de dois tipos diferentes de estímulos para participação em um experimento, já que tal fator poderia ter impactos motivacionais e é uma diferença de difícil controle. Outros fatores como experiência com a língua, idade e inteligência geral foram estatisticamente controlados.

\subsection{Materiais utilizados no experimento}

\subsubsection{O teste de reconhecimento de Autores (The Author Recognition Test - ART)}

Como é estabelecido pelos próprios autores e de acordo com extensa e bem fundamentada literatura específica, a análise e aferição de comportamentos de leitura é muito fragilizada pelas pressões sociais a esta relacionadas. Eles argumentam que conhecer autores e livros é normalmente tido como socialmente desejável, como fator de afirmação de amplitude de referências culturais, sofisticação e inteligência. Para resolver esta questão de maneira que este desejo de afirmação não influencie resultados, o ART foi desenhado. 
Segundo Mar e colegas, o teste de reconhecimento de nomes de autores é especialmente hábil em evitar adivinhações ou "chutes" pois os respondentes são informados de antemão que dentre as listas de nomes de autores das quais terão que separar aqueles que conhecem, estarão misturados nomes de personagens-contraponto (foils). Como é reconhecido por Mar e colegas, o teste não é uma medida direta de leitura efetiva de autores, mas sim uma medida de familiaridade com os nomes. Eles entendem que é uma condição bastante comum que pessoas conheçam mais autores do que aqueles sobre os quais efetivamente se debruçaram. Orelhas de livros, comentários, livros de referências, manuais, histórias da literatura, aulas, links com sugestões de leitura, comentários de terceiros, buscas em bibliotecas, conversas com amigos, todos esses mecanismos podem ofertar informações sobre autores sem que a leitura efetiva dos mesmos esteja implicada. Ainda assim, os investigadores do experimento aqui em pauta argumentam que diversos e bem fundados experimentos de validação mostram que bons resultados no ART podem ser correlacionados estatisticamente com habilidades e hábitos de leitura tais como habilidade de leitura precoce (CUNNINGHAM \& STANOVICH, 1997), frequência de leitura no mundo real (WEST, STANOVICH, \& MITCHELL, 1993), habilidade refinada de leitura (STANOVICH \& WEST, 1989). Mesmo a capacidade de aquisição de conhecimento em função de capacidade cognitiva foi estatisticamente controlada para que se possa entender especificamente como a exposição a narrativas em pessoas com diferentes coeficientes cognitivos pode elicitar tais capacidades de leitura e compreensão (STANOVICH \& CUNNINGHAM, 1993; WEST, STANOVICH e MITCHELL, 1993).

Segundo reportado por Mar e colegas, o ART foi especialmente redesenhado para esse experimento. Como samples de ficção foram usados 50 autores divididos em grupos de 10 em 5 categorias distintas: Romance, Sci-Fi/Fantasia, Suspense/Thrillers, Ficção Doméstica $^{2}$ e Autores Estrangeiros traduzidos ao Inglês. Considerando que estamos aqui

2 O termo original "Domestic Fiction" expressa um tipo de literatura caudatário daquilo que no século XVIII chamava-se "sentimental novel", "sentimental fiction", "novel of sensibility". Entretanto, o termo atualmente remete a autores que herdaram o tema das relações familiares e afetivas mas que, naturalmente, pelo momento histórico, geralmente, trabalham com conceitos menos idealizados de família e amor romântico. Note-se que nesse gênero ou subgênero é menos definido no mundo literário em geral, entretanto, bem mais consolidado como tal, na ambiência norte-americana (Estados Unidos e Canadá). No artigo que aqui analiso "Domestic Fiction" apresenta samples muito heterogêneos, estando no mesmo balaio autores como John Updike (a mistura da verborragia com a sutileza na crítica do desmonte da família americana de classe média e dos infantilismos e irresoluções de adultos americanos), John Irving (e seus planos repetidos como prefiguração de um fatalismo trágico em livros que claramente começam a ser escritos pelo epílogo) Carol Shields (exploração da novela doméstica sentimental na interface com a "biografia" familiar inventada) e 
escrevendo para um público prioritariamente de literatura, não me sentiria à vontade de omitir a lista de autores que pode ser interessante para vocês, leitores :

Romance: Sidney Sheldon, Danielle Steele, Jackie Collins, Judith Krantz, Nora Roberts, Iris Johansen, Diana Palmer, Catherine Anderson, Joy Fielding, Nicholas Sparks.

Sci-Fi/Fantasia: Robert Jordan, Douglas Adams, Anne McCaffrey, William Gibson, Terry Brooks, Terry Goodkind, Piers Anthony, Arthur C. Clarke, Ray Bradbury, Ursula K. Le Guin.

Suspense/Thrillers: Dean Koontz, John LeCarré, Robert Ludlum, Clive Cussler, Sue Grafton, Ian Rankin, P. D. James, John Saul, Patricia Cornwell, Ken Follett.

Ficção Doméstica: John Updike, W. O. Mitchell, Alice Munro, Maeve Binchy, Carol Shields, John Irving, Toni Morrison, Amy Tan, Rohinton Mistry, Sinclair Ross.

Estrangeiros traduzidos: José Saramago, Yukio Mishima, Gabriel García Márquez, Albert Camus, Umberto Eco, Milan Kundera, Paulo Coelho, Italo Calvino, Thomas Mann.

Outros 50 autores foram usados para não ficção divididos em grupos de 10 em 5 categorias: Ciência, Filosofia /Psicologia, Comentário Social/Político, Autoajuda e Negócios.

Ciência: Stephen Hawking, Stephen J. Gould, Richard Dawkins, Thomas Kuhn, Ernst Mayr, Douglas Rushkoff, Amir D. Aczel, Matt Ridley, John Maynard Smith, Diane Ackerman.

Filosofia/Psicologia: Roland Barthes, John Searle, Jean Baudrillard, Michel Foucault, Bertrand Russel, António Damásio, Daniel Goleman, Jeffrey Gray, Joseph LeDoux, Oliver Sacks,

Comentário Social/Político: Noam Chomsky, Norman Mailer, Michael Moore, Eric Schlosser, Bob Woodward, Pierre Berton, Naomi Klein, Naomi Wolf, Robert D. Kaplan, Susan Sontag.

Alice Munro (narrativa simples em favor de caracterizações didáticas de sensibilidades) etc. 
Autoajuda: Jack Canfield, Philip C. McGraw, M. Scott Peck, Robert Fulghum, Erma Bombeck, Jean Vanier, Stephen R. Covey, Melody Beattie, Deepak Chopra, Marianne Williamson.

Negócios: Faith Popcorn, Jim Collins, Napoleon Hill, Robert T. Kiyosaki, Stephen C. Lundin, Peter S. Pande, Kenneth H. Blanchard, Peter F. Drucker, Barry Z. Posner, M. D. Johnson Spencer.

Como personagens, 40 Foils (personagens-contraponto) foram usados : Lauren Adamson, John Condry, Martin Ford, James Morgan, Eric Amsel, Edward Cornell, Harold Gardin, Scott Paris, Margaritia Azmitia, Carl Corter, Frank Gresham, Richard Passman, Oscar Barbarin, Diane Cuneo, Robert Inness, David Perry, Reuben Baron, Denise Daniels, Frank Keil, Miriam Sexton, Gary Beauchamp, Geraldine Dawson, Reed Larson, K Warner Schaie, Thomas Bever, Aimee Dorr, Lynn Liben, Robert Siegler, Elliot Blass, W Patrick Dickson, Hugh Lytton, Mark Strauss, Dale Blyth, Robert Emery, Franklin Manis, Alister Younger, Hilda Borko, Frances Fincham, Morton Mendelson.

Os autores atestam que grande esforço foi empenhado para garantir que autores de ficção escolhidos não tivessem escrito livros dissertativos ou expositivos e que autores selecionados de não ficção tivessem apenas escrito livros não narrativos. No entanto, alguns pequenos problemas poderiam ser notados na lista, neste sentido, apesar de minha muita ignorância em relação ao trabalho de vários desses autores norte-americanos. Albert Camus, para muitos, um filósofo; para outros um ensaísta; para muitos outros, um filósofo-ensaísta, é categorizado como autor de ficção. Poder-se-ia argumentar que tanto sua ficção tem pendor filosófico quanto seus ensaios têm pendor literário. Umberto Eco também tem claramente produção em áreas narrativas e dissertativas, com contribuições para a semiologia, filosofia e linguística, além da literatura. Carol Shields, estadunidense de nascimento e radicada no Canadá, escreveu vasta obra narrativa e outrossim biografias (entre estas, a mais notória: Jane Austen, a Life). Considerando que a lista compreende 100 nomes, o deslize não é tão grave mas, ainda assim, notável. Outros comentários sobre distinções nas categorias tanto por gêneros literários como por áreas não ficcionais poderiam ser aqui tecidos, mas entendo que são muito pouco relevantes para a validade do experimento e para sua compreensão. Só não consigo, caros leitores, refrear minha 
estranheza como aprendiz de filósofo da ciência em ver o filósofo da ciência Thomas Kuhn colocado com um cientista e não como um filósofo.

De qualquer maneira, considerando extensa e diversa literatura sobre medidas de familiarização com literatura, parte da qual citada acima, os autores argumentam que essa versão atualizada e especializada do ART é eficiente em aferir de maneira diferenciada a exposição a textos narrativos e dissertativos e os argumentos são razoavelmente convincentes, já que outras medidas de mesma natureza já foram cruzadas com o ART e neste experimento específico serão utilizadas como pedras de toque e comparação, por exemplo, testes de autodeclaração e outros métodos a serem descritos abaixo.

\subsection{2 Índice de Reatividade Interpessoal (The Interpersonal Reactivity Index -IRI)}

Como uma medida de aferição de empatia de diversos tipos, o experimento aqui em questão usa do IRI (DAVIS, 1980), já bastante consolidado. Como é mostrado pelo próprio criador do índice, a estrutura dimensional foi validada e pode ser cruzada com outras ferramentas de avaliação de empatia de maneira sólida (DAVIS, 1983). Tal índice é uma medida composta de 28 itens de autodeclaração de empatia multidimensional contendo 4 subescalas: (1) Fantasia, (2) Tomada de Perspectiva, (3) Preocupação Empática (4) Aflição Pessoal.

Os participantes marcam numa escala de 5 pontos o nível que as declarações lhes contemplariam ou os descreveriam. Exemplos fornecidos pelos autores de tais itens seriam os seguintes: "Eu tento olhar o lado de todo mundo em uma desavença antes de tomar uma decisão" (Tomada de Perspectiva), "Eu fico usualmente tocado(a) por coisas que eu vejo" (Preocupação Empática) e "Estar numa situação tensa emocionalmente me dá medo" (Aflição Pessoal).

Notem que não falei especificamente dos itens relacionados a "Fantasia". Este é um ponto crucial para o entendimento desta parte específica do experimento que está sendo aqui analisado. A subescala "Fantasia" foi tratada como uma medida de transposição narrativa, como é assumido por Mar e Colegas. Eles atestam que ela foi eleita como uma medida da capacidade autodeclarada de se colocar em uma narrativa. As sentenças presentes em tal subescala são as seguintes: 
a) "Eu sonho acordado e fantasio com alguma regularidade sobre coisas que podem acontecer comigo";

b) "Eu realmente me envolvo com os personagens de um romance";

c) "Tornar-me envolvido em um bom livro ou filme é de alguma maneira raro para mim" (sentença negativamente contada);

d) "Depois de ver uma peça ou filme eu me sinto como se eu fosse assim um de seus personagens".

Concordo com os autores que uma leitura dos itens de tal subescala mostra que ela é predominantemente um índice de engajamento em narrativas. Os autores concedem que o primeiro item não tem exatamente esta natureza e seria uma exceção, no que também concordo com os autores, mas entendo que, se tal item não é marcado pelo caráter de transposição narrativa, ele, ao seu turno, demarca uma capacidade de envolvimento criativo em uma narrativa, de transposição para uma situação imaginária que, muitas vezes, envolve o romanceamento com pessoas reais ou imaginárias, situações sociais onde a projeção narrativa, por mais fantasiada que possa ser, resguardaria algumas características com as regras de transposição para situações não determinadas exclusivamente por desejos e projeções pessoais. Mas, naturalmente, não querendo defender os autores mais do que eles próprios, tal declaração é menos demarcadora da capacidade de projeção em uma história que tem determinações exógenas à vontade de quem se projeta e, assim, apresenta menos objetividade para regras de interação social ou para o acompanhamento de uma narrativa. Ela é mais pautada pela capacidade de construir uma narrativa pessoal e menos pela capacidade de se projetar em uma situação interpessoal empática ou se transpor para uma narrativa.

\subsubsection{Lendo a Mente nos Olhos (The "Reading the Mind in the Eyes" Test-revised - MIE)}

Os autores do artigo em pauta fazem uso de ainda mais dois testes, sendo que neste subcapítulo explico a vocês, leitores, o MIE (BARON-COHEN, WHEELWRIGHT, HILL, RASTE, PLUMB, 2001). O teste em tela investiga a capacidade de inferir ou interpretar estados mentais a partir de expressões de fotos da área dos olhos de atores. Diante de uma foto da região dos olhos de uma pessoa com uma expressão determinada, ampla e previamente 
correlacionada cientificamente com um estado mental, os participantes são perguntados qual entre 4 estados mentais corresponderia àquela expressão de olhar. Como afirmado pelos investigadores, o teste em questão foi originalmente (Ibidem, 2001) aplicado para indivíduos com autismo de alto funcionamento e síndrome de Asperger e controles com Ql pareado. Os primeiros dois grupos têm escores menores comparados aos controles e os escores não apresentam correlações com índices de Ol podendo, assim, serem especificamente correlacionados com capacidades de percepção social (Ibidem, 2001).

\subsubsection{Tarefa de Percepção Interpessoal (The Interpersonal Perception Task-15 - IPT-15)}

Conforme explicado pelos autores do nosso estudo em questão, o ITP-15 (COSTANZO \& ARCHER, 1993) consiste em um vídeo sem roteiro prévio com 15 situações de interação social entre 2 ou mais indivíduos que são apresentados aos participantes. Após cada uma das 15 vinhetas, os participantes têm de julgar questões de múltipla escolha que têm respostas objetivas, mas nunca apresentadas nas situações presentes no filme de maneira explícita, tendo os respondentes que inferir a partir de indicações tácitas, dinâmicas e não verbais tais como prosódia, gestos, posturas etc, a resposta correta. O exemplo fornecido pelos autores do estudo aqui em análise de uma pergunta presente no teste é "Quem é o filho dos dois adultos?". Como afirmado pelos autores do estudo em análise, os escores nessa medida são amplamente correlacionados com avaliações de pares sobre a sensibilidade interpessoal e habilidades sociais (CONSTANZO \& ARCHER, 1989).

Em todos os protocolos experimentais aqui relatados, idade, anos de experiência com a língua inglesa e inteligência, como já foi reportado anteriormente, foram controlados para que de fato pudesse ser traçada uma correlação mais forte, especificamente, entre a exposição à ficção narrativa e a posse de habilidades sociais. Como medida geral de inteligência foi usado um dos subtestes de raciocínio perceptual do WAIS-IV (Wechsler Adult Intelligence Scale, $4^{\mathrm{a}}$ edição), no caso o teste de raciocínio de matrizes. Ainda que WAIS-IV seja altamente testado e possa ser, para muitos, uma boa medida para a aferição geral de inteligência, é passível de crítica que os pesquisadores do nosso estudo em tela tenham usado apenas uma bateria de subtestes entre o total de 15 presentes no teste como um todo. É, naturalmente, explicável que esta é apenas uma medida de controle, uma baliza para aferição genérica de inteligência e que em um estudo que já é claramente multifatorial 
e composto de vários subestudos, a aplicação de mais um teste de ampla extensão e multifatorial, também ao seu turno, seria mais um sem fim de informação a ser processada, além de um grande gasto de tempo. Os autores citam Jensen (1998) como um defensor de que o subteste de raciocínio matricial do WAIS-IV seja o melhor indicador único de fator de inteligência geral. No entanto, não fui capaz de achar no texto citado nenhuma afirmação desta natureza com diversas buscas direcionadas. Nem fui capaz de inferir isto das tabelas do livro em questão. Pode ser que a falha seja minha. Naturalmente, não pude reler o livro inteiro de Jensen (66o páginas), mas usei de buscas direcionadas com mais de 12 tipos de frases, truncagens e expressões de busca com sinônimos vários, radicais dos termos, e li todas as tabelas. Não achei... Mesmo que tal fator fosse indicado como o mais confiável, o WAIS está na sua quarta edição e passou por mudanças consideráveis desde a publicação do livro de Jensen (1998). E, naturalmente, como todo teste de QI, não é livre de críticas, ainda que seja muito consagrado.

Uma possibilidade mais refinada não explorada pelos autores seria usar o subteste específico de compreensão verbal contraposto e "descontado" do resto do teste como um todo. Isso daria uma noção mais fidedigna da diferença entre exposição à narrativa e competência linguística mais em geral. Além disso, tal medida permitiria três diferenciações: inteligência geral, competência de compreensão verbal e exposição à narrativa. No entanto, deve-se notar que, além dos problemas já apontados no parágrafo anterior sobre multifatorialidade e quantidade de informação, existem outros problemas, de natureza experimental prática. Ter os mesmos sujeitos experimentais disponíveis por tanto tempo não é a coisa mais corriqueira e fácil (mesmo no caso de sujeitos remunerados e especialmente no caso de voluntários sem remuneração). Além disso, manter o sujeito em ambiente laboratorial por horas a fio, em grandes sequências de baterias de estudos, pode gerar sobrecarga cognitiva e profundo cansaço, comprometendo a performance dos sujeitos nas últimas baterias. Não obstante a melhoria de protocolo por mim sugerida (que para ser aplicável pressupõe tempo e dinheiro, cada vez mais escassos na vida de pesquisadores) fortaleceria ainda mais o resultado geral do experimento que já é por si só bem fundamentado. 


\subsection{Resultados e discussão (dos próprios autores e a minha)}

Como resultados principais do estudo, segundo seus próprios autores, podemos listar uma correlação positiva entre a exposição à ficção narrativa e a relação oposta para não ficção dissertativa. Os resultados, seguindo a análise dos próprios autores, parece questionar uma visão intuitiva e amplamente difusa no senso comum de que "ratos de biblioteca" sejam pessoas antissociais, com dificuldades de entrosamento ou compreensão de dinâmicas de interação e com personalidades peculiares e distantes. É sugerido pelos autores que o estereótipo do "rato de biblioteca" como um sujeito esquisito, com óculos de fundo de garrafa, socialmente desfuncional, é talvez mais apropriado ou pelo menos mais passível de ser atribuído aos assim chamados "nerds". É, também, conjecturado pelos autores que os ditos "ratos de biblioteca" poderiam, mesmo que tendo contato interpessoal reduzido por horas de leitura solitária, ter os efeitos nocivos dessa pouca prática e vivência social minimizados pela capacidade de simulação, empatia e projeção das situações sociais retratadas no vasto contato que teriam com narrativas ficcionais romanescas. Já o mesmo não aconteceria com os alcunhados "nerds", que não seriam capazes de desenvolver essa capacidade imaginativa e simulatória, visto que o acesso prioritariamente voltado para leitura não ficcional poderia representar um déficit de desenvolvimento de capacidade social projetiva. Apesar do termo não ser usado em momento nenhum do artigo, permitirme-ei conjecturar que uma das formas mais eficazes de colocar um dos pontos fundamentais desse debate é pensar esta relação em termos de uma metaintencionalidade projetiva. Ainda que possamos inferir em situações cotidianas intenções por gestos de outrem, de maneira tácita, como por exemplo é o caso comum entre humanos e diversas espécies sociais não humanas, sem necessariamente sofisticação linguística, a leitura de narrativas romanescas poderia ser tida como possivel fonte de treinamento de capacidades imaginativas pela via da significação de uma metaintenção do leitor, formada com base na significação da intenção de um personagem. Quando o leitor, em um primeiro momento, fica em dúvida se, em Ulysses, Leopold parece, "de fato", estar fomentando o adultério de Molly e logo depois entende que essa intenção é clara e, a partir dessa conclusão, começa a conjecturar se Leopold o faz por gentileza, culpa ou interesse econômico (ou a conjunção desses fatores e quiçá outros), ele estaria exercitando sua capacidade de interpretação social por imaginação, projeção e simulação das situações em diversos níveis intervenientes 
e complexos. Sem dúvida que o relativismo e subjetivismo de uma narrativa dessa monta são mais desafiadores em termos de desenvolvimento e aplicação de capacidades metaintencionais do que saber que o nariz tão grande da "vovó" é para sentir melhor o cheiro de Chapeuzinho e a boca tão grande é para comê-la. Mas, como sugere o estudo de Cunningham \& Stanovich (1997), talvez ler, na mais tenra infância, o conto de fadas (que Charles Perrault hauriu do folclore francês) facilite sobremaneira ler (e entender) Joyce quando "adulto literário".

No entanto, como os próprios autores do nosso estudo em tela concedem, o que os resultados são capazes de sustentar é apenas uma correlação entre exposição à narrativa ficcional e habilidades sociais e uma correlação oposta entre exposição à leitura não ficcional expositiva e capacidades de relação e interpretações interpessoais. Segue, ainda, não passível de afirmação peremptória qual seja a direcionalidade da causalidade desta relação.

\section{O que você lê faz diferença}

Em um artigo intitulado "What You Read Matters: The Role of Fiction Genre in Predicting Interpersonal Sensitivity", Katrina Fong, Justin B. Mullin e Raymond A. Mar, com base nos estudos anteriores, partindo da relação positiva entre exposição à ficção e sensibilidade intersubjetiva, vão abordar a questão de como a exposição a distintos gêneros ficcionais teria correlações de diferentes magnitudes com as capacidades sociais de seus leitores. Esse follow-up é extremamente bem-vindo no que concerne a uma diferenciação de como diferentes gêneros literários poderiam ser mais ou menos correlacionados a capacidades sociais. Diferentemente do primeiro experimento, o estudo aqui abordado não foi capaz de replicar o resultado de uma correlação negativa entre exposição à não ficção dissertativa e capacidades sociais. Mas o estudo replica os resultados anteriores no que concerne à correlação positiva entre exposição à ficção narrativa. Oportunamente, o experimento que será agora analisado é capaz de dar um importante passo além do primeiro dos experimentos aqui apresentados, no qual a relação entre exposição à ficção narrativa e habilidades sociais já era bem estabelecida: nesse novo artigo, o Romance é aferido como gênero de maior correlacionamento com sensibilidade social. Como esperado, os gêneros de ficção que focalizam mais profundamente relações interpessoais têm 
correlações mais fortes com sensibilidades sociais que outros gêneros, onde tal relação não é a tônica central. Imagino que o estudioso de narrativas romanescas nesse momento se sinta como o torcedor que leva ao estádio o prosaico e nem tão engraçado cartaz com o dizer "eu já sabia" e que o levanta diante da vitória. Mas diferentemente do Oráculo, para o qual, se a realidade lhe discordar, quem está errada é esta, ou de Dostoiévski (que afirmara: "Se me provarem que a verdade não está em Cristo, prefiro deixar a verdade e ficar com Cristo"), o espírito científico vive de comprovações de hipóteses. Esses são os seus gols.

As categorias utilizadas no referido experimento são as mesmas do primeiro estudo aqui enfocado. Mas as listas de samples de obras em 4 das 5 categorias foram ampliadas de 10 para 25 autores (Romance, Ficção Doméstica, Sci-Fi/Fantasia e Thriller/Suspense). Na categoria "literatura estrangeira traduzida ao inglês" foram mantidos os 10 autores originais. Note-se que os autores mantiveram a categoria "literatura estrangeira traduzida ao inglês" como parte das fontes de averiguação da familiarização dos sujeitos com literatura, como parte da medida da exposição dos sujeitos experimentais à literatura, inferida a partir do reconhecimento de nomes de autores. Entretanto, não aumentaram o número dessa categoria, justamente por tratá-la como uma categoria literária, mas não como um gênero literário a ser estudado em termos de relações com capacidades e sensibilidades sociais, o que me parece uma medida acertada. Diferentemente do primeiro artigo analisado, essa lista ampliada não é ofertada ao leitor sequer nos apêndices e materiais suplementares ao estudo. De toda maneira, o aumento do número de autores em cada uma das categorias é motivado por uma necessidade de aumento da densidade estatística dos resultados particulares de cada qual das categorias. Como no primeiro estudo não se particularizam gêneros e apenas se investiga a exposição às narrativas ficcionais como um todo em contraposição à exposição a material de leitura expositivo não ficcional, temos uma disjunção simples entre 2 categorias e não é necessário um número tão grande de autores em cada um dos gêneros. Como esse follow-up visa entender como cada gênero relacionase com capacidades e sensibilidades sociais, o número é aumentado para ser viável trabalhar estatisticamente com 4 categorias representadas por cada um dos gêneros em questão (Romance, Novela Doméstica, Sci-Fi/Fantasia e Thriller/Suspense). É claro que muita controvérsia em teoria literária poderia ser levantada diante dessas categorias serem as escolhidas e, mesmo, poderia ser levantado o debate de fundamentos se tais categorias se enquadram propriamente na condição de gêneros ou subgêneros literários. No entanto, 
por questões de limitação temporal, de limites de páginas deste artigo e mesmo da minha pouca familiaridade com a vasta e discordante literatura específica sobre definição de gêneros literários, não adentrarei tal debate.

Mas, voltando a detalhar um pouco mais a estrutura de realização do estudo, neste experimento, a população foi composta exclusivamente de estudantes universitários canadenses que receberam, como "remuneração", créditos parciais em uma disciplina. Note-se que a este follow-up, não recai minha crítica anterior direcionada ao experimento original que dispunha de duas formas distintas de estímulo à participação dos sujeitos experimentais (dinheiro ou créditos em disciplina). Dos registros de 368 participantes que completaram o experimento originalmente, os dados de 328 foram incluídos nas análises (258 mulheres). Considerando que o estudo enfocava literatura publicada única e exclusivamente em inglês (e o Canadá, além de um país bilíngue tem vasta gama de imigrantes), foram excluídos participantes com menos de 9 anos de experiência na língua inglesa. Esta é apenas uma medida de controle básico da expertise na língua, e é, naturalmente, bem-vinda. Outro ponto a ser notado é que a população experimental desse estudo é quase três vezes e meia maior do que aquela do primeiro experimento, o que é um fator de maior confiabilidade estatística.

Além do uso do ART-R (a versão revista do Author Recognition Test), foi usado também um outro protocolo também presente no primeiro experimento o MIE (Reading the Mind in the Eyes Test), dessa vez numa versão também revisada. Desta feita, o IRI aplicado no primeiro experimento (The Interpersonal Reactivity Index) não foi usado.

Outro teste não presente no primeiro experimento aqui analisado é introduzido como forma de controle, o BFI (Big Five Inventory). Este último é um teste que explora as assim chamadas cinco grandes dimensões de personalidade: extroversão vs. introversão, amabilidade vs. antagonismo, conscienciosidade vs. falta de direção, abertura para a experiência vs. fechamento, neuroticismo vs. estabilidade emocional. O teste é constituído de 44 frases curtas que devem ser avaliadas em termos de concordância ou não com a personalidade do respondente numa escala de 1 a 5, com 1 representando ampla discordância, 2 pequena discordância, 3 nem concordância, nem discordância, 4 pequena concordância e 5 ampla concordância. Como se nota, é um teste de autodeclaração, e sofre de todas as mazelas que isso possa representar. Entretanto, tal teste é introduzido pelos autores do artigo em questão como uma medida de traços de personalidade que visa ser um 
controle de que a maior sensitividade social não seja devida a estes traços de personalidade e sim à exposição ao tipo de material de leitura ao que o respondente tem mais acesso.

\subsection{Resultados e debates}

Primeiramente, em termos de uma análise estatística mais genérica, os autores relatam que, usando o coeficiente de correlação de Pearson, notou-se que a exposição a material impresso estava toda relacionada. Indivíduos com mais exposição à ficção tendiam também a ter mais exposição aos subgêneros da ficção e mesmo à não ficção. Aqueles que tinham maior exposição a um subgênero também tendiam a ter mais exposição a outros. Mas, agora, começamos a enfocar aquilo que realmente pode ser especificamente interessante: seguindo estas mesmas formas de análise, os autores revelam que foi possível encontrar padrões divergentes de associação entre a exposição a certos gêneros determinados e os resultados desses participantes no teste de sensibilidade interpessoal. Como no primeiro experimento, neste follow-up, os participantes que apresentavam mais exposição à ficção obtiveram resultados mais altos nos testes de sensibilidade interpessoal e os indivíduos com maior exposição à não ficção não apresentaram essa relação. Só que, neste segundo caso, como já dito, diferentemente do primeiro experimento, em vez de se aferir uma correlação negativa entre exposição à não ficção e sensibilidade interpessoal, foi averiguada apenas a ausência de correlação. Maior exposição aos gêneros de Ficção Doméstica, Romance e Thriller/Suspense pôde ser relacionada com maiores escores no teste de sensibilidade interpessoal. Assim, todos os gêneros narrativos com exceção de SciFi/Fantasia apresentam correlações positivas com o teste de sensibilidade interpessoal, neste primeiro momento de análise. Curiosamente, por um lado, indivíduos com maior exposição tanto a ficção, não ficção e novela doméstica apresentaram correlações mais fortes com o traço de personalidade "abertura a novas experiências". Por outro lado, indivíduos com maior exposição a ficção, não ficção, ficção doméstica, Sci-Fi/Fantasia, e Suspense/Thriller apresentaram pontuação superior no traço de personalidade "introversão". É claro, conjecturas podem ser feitas em cima desses dados pouco disjuntivos e específicos, como foram feitas no primeiro artigo pelos próprios autores e agora, por mim, são feitas: pessoas que leem muito são mais abertas a novas ideias, ainda que introvertidas na lida interpessoal cotidiana? É o novo virtual, quiçá catártico ou imaginário que os coloca numa 
posição projetiva e lhes compensa as horas de reclusão solitária da leitura? Como já dito, essas são apenas conjecturas e para tentar ir além dessas relações estatisticamente precárias, os autores lançarão mão de estratégias de refinamento das análises. Vamos a elas.

Para poder individualizar as relações entre cada qual dos gêneros literários com a sensibilidade interpessoal, dirimindo problemas de multicolinearidade, o grau de exposição a cada um dos gêneros foi usado para predizer resultados no teste de sensibilidade interpessoal, dessa vez, endereçado como uma variável composta que foi calculada considerando anos de exposição e fluência em inglês, assim como foram usados gênero sexual, os traços de personalidade "abertura a novas experiências vs fechamento" e "extroversão vs. introversão" e "exposição à não ficção" como controles. Também, o número de reconhecimento de personagens-contraponto (foils) foi usado como medida de controle de padrões tendenciosos de resposta como baixo limiar para reconhecimento ("chute", "resposta de orelhada"). Outrossim, para aumentar a especificidade e relevância estatística específica de cada um dos gêneros de fato individualizados, os outros 3 gêneros foram usados como variáveis-controle.

O único resultado realmente sólido para ser apregoado cientificamente ou mesmo nas mais refinadas conversas em mesas de bar é o de que a exposição ao gênero "Romance" é fortemente correlacionada com maior sensibilidade interpessoal. Maior exposição ao gênero Romance, ao fim e ao cabo de todas as relações estatísticas, "descontos" e controles, prediz fortemente maior desempenho em testes de sensibilidade social.

\section{Conclusão}

Considerando-se apenas os estudos aqui analisados pormenorizadamente, é possível traçar correlações entre Suspense/Thriller e Ficção Doméstica com aumentada capacidade de sensibilidade interpessoal, mas estes resultados têm um grau de confiabilidade pequeno, principalmente no segundo caso que está ligeiramete abaixo da linha de relevância. Neste sentido, os autores seguem a ideia que parece estar de acordo com as nossas concepções mais intuitivas de que apenas a exposição a gêneros que afiguram relações interpessoais na própria tessitura de sua narrativa parece estar ligada a uma maior capacidade de compreensão e interpretação de situações que exigem habilidades e sensibilidades sociais. Ainda que os autores não discutam o lado literário 
desses resultados, permito-me algumas conjecturas. Logo ao começar a primeiras linhas do abstract deste artigo, imaginava que os resultados finais individualizados entre gêneros e potencial de sensibilidades intersubjetivas e capacidades sociais seriam marcados pela seguinte ordem: Romance, Ficção Doméstica (que me parece um subgênero do Romance), Thriller/Suspense, Sci-Fi/Fantasia. Logo no fim do abstract é dito que os gêneros de Romance e Thriller/Suspense eram os únicos que poderiam ser mais solidamente correlacionados com sensibilidades sociais. Refreei o meu impulso de pular a leitura do artigo como um todo e ir direto às tabelas das correlações como faria um leitor impaciente de um whodunnit e resolvi encarar o abstract como a sofrida prolepse de uma tragédia. Era importante percorrer o caminho para se entender aonde se chegava, ao fim e ao cabo. No entanto, se os resultados sugerem que o Romance é, como eu esperaria, o "primeiro colocado" no correlacionamento com habilidades e sensibilidades sociais, eu via uma surpresa, uma inversão de minhas expectativas em relação ao segundo com o terceiro "colocados". Aqui uma série de conjecturas poderia ser feita. Por que a exposição à Ficção Doméstica, ainda que esta seja prioritariamente um gênero fundado em relações pessoais e afetivas é menos preditora de bons resultados em testes de sensibilidade interpessoal do que a exposição a Thriller/Suspense? Seria, simplesmente, devido às limitações estatísticas do experimento (como é assumido pelos autores como uma possibilidade)? Seria pelo fato de que os samples presentes na categoria ficção doméstica são formas mais simples de narrativa? Seria pelo fato de que elas demandam capacidades projetivas mais simples por afigurarem situações mais comezinhas e corriqueiras? Seria pelo fato de que Suspense/Thriller demanda maior capacidade de projeção em planos obscuros e intenções veladas de personagens, requerendo uma metaintencionalidade mais arguta? Seria pelo fato de que a logicidade e consequencialismo de comportamentos no suspense é simplesmente cognitivamente mais demandante? Ficam aqui as minhas dúvidas quanto à questão literária. De qualquer maneira, como os próprios autores reconhecem, no plano científico, replicação e novas estratégias de controle e isolamento de variáveis são importantes para uma maior clareza das correlações e para qualquer pretensão de estabelecimento ulterior de relações causais. O que sem dúvida seria cada vez mais bemvindo é a interação consiliente entre literatos, filósofos e cientistas para trabalharem numa agenda comum. 


\section{Referências bibliográficas}

ARISTOTLE. Poetics. Tradução de S.H. Butcher. Nova lorque: Cosimo Classics, 2008.

BAKHTIN, M. The Dialogic Imagination: Four Essays. Austin: University of Texas Press, 1981.

BARON-COHEN et al. The "Reading the Mind in the Eyes" test revised version: A study with normal adults, and adults with Asperger's syndrome or highfunctioning autism. Journal of Child Psychology and Psychiatry, 42, 241-251, 2001.

CARRUTHERS, P.; SMITH, P. K. (Eds.) Theories of theories of mind. Cambridge, MA: Cambridge University Press, 1986.

COSTANZO, M.; ARCHER, D. Interpreting the expressive behaviour of others: The Interpersonal Perception Task. Journal of Nonverbal Behavior, 13, 225-245, 1989.

COSTANZO, M.; ARCHER, D., The Interpersonal Perception Task-15 (IPT-15): A guide for researchers and teachers. Berkeley, : University of California, Extenstion Center for Media and Independent Learning, 1993.

CUNNINGHAM, A. E.; STANOVICH, K. E. Early reading acquisition and its relation to reading experience and ability 10 years later. Developmental Psychology, 33, 934-945, 1997.

DAVIS, M. H. A multidimensional approach to individual differences in empathy. JSAS Catalogue of Selected Documents in Psychology, 10, 85, 1980.

DAVIS, M. H. Measuring individual differences in empathy: Evidence for a multidimensional approach. Journal of Personality and Social Psychology, 44, 113-126, 1983.

FONG, K. MULLIN, J.B., MAR, R.A., What You Read Matters: The Role of Fiction Genre in Predicting Interpersonal Sensitivity, Psychology of Aesthetics, Creativity, and the Arts American Psychological Association, Vol. 7, No. 4, 370-376, 2013.

FRITH, U. E FRITH, C. D. The biological basis of social interaction. Current Directions in Psychological Science, 10, 151-155, 2001.

MAR, R. A. et al. Bookworms versus nerds: Exposure to fiction versus non-fiction, divergent associations with social ability, and the simulation of fictional social words. Journal of Research in Personality, 40, 694-712, 2006.

MAR, R. A.; OATLEY, K.; PETERSON, J. B. Exploring the link between reading fiction and empathy: Ruling out individual differences and examining outcomes. Communications, 34, 407-428, 2009.

MOGRABI, G.J.C. Sobre Naturalismos, Resistências Humanistas e a possibilidade de diálogo. Recife: Eutomia, 14 (1): 419-445, Dez, 2014. 
NUSSBAUM, M. C. Poetic justice: The literary imagination and public life. Boston, MA: Beacon, 1995 .

SHIELDS, C.D. Jane Austen: A Life. Nova lorque:Lipper/Viking - Penguin Books Group, 2005.

STANOVICH, K. E.; WEST, R. F. Exposure to print and orthographic processing. Reading Research Quarterly, 24, 402-433, 1989.

STANOVICH, K. E.; CUNNINGHAM, A. E. Where does knowledge come from? Specific associations between print exposure and information acquisition. Journal of Educational Psychology, 85, 211-229, 1993.

WEST, R. F.; STANOVICH, K. E.; MITCHELL, H. R. Reading in the real world and its correlates. Reading Research Quarterly, 28, 34-50, 1993.

i Gabriel José Corrêa MOGRABI, Prof. Dr. Universidade Federal do Mato Grosso (UFMT)

Departamento de Filosofia

E-mail: gabriel.mograbi@gmail.com

Recebido em 19/04/2015

Aceito em 22/06/2015 